\title{
Bilateral carotid aneurysms unmasked by severe hypopituitarism
}

\author{
Alain Michils, Danièle Balériaux' and Jean Mockel
}

Departments of Endocrinology and ${ }^{1}$ Radiology, Erasme Hospital, Université Libre de Bruxelles, B-1070 Brussels, Belgium

\begin{abstract}
Summary: We describe a patient who initially presented with severe hyponatraemia and grand mal seizures, without any focal neurological symptoms. The final diagnosis was that of giant bilateral carotid aneurysms extending into the sella turcica with anterior hypopituitarism. To the best of our knowledge, this is the first case report of symmetrical carotid aneurysms manifested exclusively by an acute endocrine emergency with none of the concomitant usual focal signs such as headache, failing vision, oculomotor palsy or subarachnoid hemorrhage.
\end{abstract}

\section{Introduction}

Carotid aneurysms mimicking pituitary tumours are responsible for parasellar syndromes with neurological and mass effect symptoms dominating the clinical presentation. ${ }^{1-5}$ The patient reported is exceptional in two ways. Firstly giant bilateral intracavernous carotid aneurysms were present and secondly the grand mal seizures leading to diagnosis resulted from severe hyponatraemia related to an anterior hypopituitarism, with none of the usual symptoms of parasellar syndromes.

\section{Case report}

A 73 year old woman was transferred to our hospital because of grand mal seizures and persistent hyponatraemia. Nine months earlier, she had been admitted to another hospital for transient diplopia resulting from sudden palsy of the right external oculomotor muscle. The only neurological investigation performed was a normal electroencephalogram. The diplopia disappeared within a few days, with a diagnosis of transient cerebral ischaemia. Five months prior to admission, the patient noted progressive weight loss, increasing fatigue and severe orthostatic dizziness with falls. During this period, she was hospitalized three times in another hospital, where hyponatraemia (115- $125 \mathrm{mmol} / \mathrm{l})$ was repeatedly documented but remained without valid explanation. When increasing confusion and grand mal seizures occurred, the patient was finally transferred to our hospital.

Correspondence: J. Mockel, M.D., Ph.D.

Accepted: 20 September 1990
On arrival, the patient was alert. Physical examination disclosed no abnormality, except weak but equal tendon reflexes. There was no diplopia. Serum sodium was $125 \mathrm{mmol} / \mathrm{l}$ with inappropriate renal sodium losses $(113 \mathrm{mmol} /$ day in the $24 \mathrm{~h}$ urine collection), potassium was $3.2 \mathrm{mmol} / \mathrm{l}$ (28 $\mathrm{mmol} /$ day in urine), plasma osmolality was low at $262 \mathrm{mOsm} / \mathrm{kg}$ with diluted urines $(386 \mathrm{mOsm} / \mathrm{kg}$ in the $24 \mathrm{~h}$ collection). The urea nitrogen was $3.2 \mathrm{~mol} / 1$, creatinine $106 \mu \mathrm{mol} / 1$ and uric acid $0.17 \mathrm{mmol} / \mathrm{l}$. There was a slight normochromic normocytic anaemia with a haemoglobin at $104 \mathrm{~g} / \mathrm{l}$. An X-ray film of the chest was normal, while the standard skull X-ray showed an enlarged sella turcica due to bony destruction of the floor of the sella and of the anterior and posterior clinoids.

The provisional symptomatic treatment included restriction of fluid intake, administration of intravenous hypertonic saline and frusemide, and of oral urea. Thyroid function tests showed: thyroxine $55.0 \mathrm{nmol} / 1$ (normal 80.6-154), triiodothyronine $0.51 \mathrm{nmol} / 1$ (normal $1.3-3$ ), TSH $0.14 \mathrm{mU} / \mathrm{l}$ (normal $0.2-5.5$ ), an $08.00 \mathrm{~h}$ plasma cortisol was $143.5 \mathrm{nmol} / \mathrm{l}$ (normal 248-690) and a free $24 \mathrm{~h}$ urinary cortisol $65 \mathrm{nmol}$ (normal 55-276); LH was $<0.4 \mathrm{mg} / 1$ (normal post menopausal $>5,5$ ) and FSH $0.5 \mathrm{mg} / 1$ (normal post menopausal $>11$ ); GH was $<0.75 \mathrm{mg} / 1$ (normal $<5.5$ ) and somatomedin $\mathrm{C} 0.2 \mathrm{U} / \mathrm{ml}$ (normal $0.4-1.5$ ), prolactin was $1400 \mathrm{mU} / 1$ (normal $<240$ ). Because of the critical clinical situation of the patient no further dynamic tests were performed, except a diagnostic and therapeutic intramuscular injection of corticotrophin (Synacthen $\operatorname{depôt}^{\mathrm{R}} 2 \mathrm{mg}$ ). Plasma cortisol peaked to high values within 2 days, while serum sodium normalized and $24 \mathrm{~h}$ natriuria fell to low values. 
The neuroradiological images are shown in Figure 1. Computed tomography scan demonstrated an intra- and parasellar non-homogeneous space occupying lesion. The tumour enhanced homogeneously and vividly after intravenous contrast injection. A digital angiography demonstrated that the mass resulted from bilateral intracavernous giant carotid aneurysms extending into the sellar cavity. In a magnetic resonance imaging (MRI) study, a series of sagittal $T_{1}$ weighted images as well as two series of coronal $T_{2}$ weighted images centred on the sellar region were obtained: bilateral aneurysms of the carotid siphons could specifically be diagnosed due to the characteristic black appearance of the lesions on all images (flow void phenomenon). Fundoscopic examination, visual acuity and visual field testing were normal.

Surgical treatment was considered unreasonable and discarded since it implied ligation of both internal carotid arteries. Medical treatment with cortisone acetate $25 \mathrm{mg}$ and $l$-thyroxine $125 \mu \mathrm{g}$ daily rapidly resolved the hyponatraemia and abolished all symptoms presented by the patient

\section{Discussion}

The present case report illustrates the exceptional situation where bilateral intracavernous carotid aneurysms presented as a severe hyponatraemia resulting from anterior pituitary insufficiency.

Symptomatic hyponatraemia, as initial symptom of hypopituitarism is, by itself, unusual, ${ }^{6}$ although classically described., ${ }^{7,8}$ In our own experience, however, hyponatraemia was the symptom leading to hospitalization and diagnosis in 12 out of 40 patients with complete pituitary insufficiency (personal data). The hyponatraemia in such situations is generally attributed to an increased secretion of $\mathrm{ADH}$ and greater sensitivity to its action of the collecting tubules resulting from glucocorticoids and thyroid hormone deprivation, ${ }^{8-10}$ although hyporeninism has also been held responsible for abnormal sodium losses. ${ }^{7}$

Hypopotuitarism results in the majority of cases from hypophyseal tumours and/or Sheehan's syndrome in older series, amounting to $59 \%$ of all cases in a report collecting 1060 pituitary insufficiencies. ${ }^{6}$ The next most frequent aetiologies are intra- or parasellar tumours such as craniopharyngiomas, meningiomas and germinomas, trauma, irradiation, and previous surgery in the sellar region. ${ }^{6,11}$

Carotid artery aneurysms mimicking pituitary tumours are uncommon but well described. ${ }^{1-3}$ They can account for up to $10 \%$ of the lesions causing a parasellar syndrome, ${ }^{2}$ while $1.4 \%$ to $5 \%$ of all intracranial aneurysms referred to neurosurgeons projected into the sella turcica in other series. ${ }^{4,5}$

However, pituitary dysfunction is thought to be rare in patients with intracavernous aneurysms of $\frac{\varrho}{c}$ the internal carotid artery, ${ }^{12}$ the absence of endocrine symptoms even being considered as an impor- $\underset{\vec{S}}{\vec{S}}$ tant diagnostic feature to differentiate aneurysms from pituitary adenomas. ${ }^{13}$ Aneurysms were not described as cause of hypopituitarism in a review by Sheehan and Summers. ${ }^{14}$ More recent literature $\overparen{\nabla}$ did, however, report the coincidental occurrence of

a

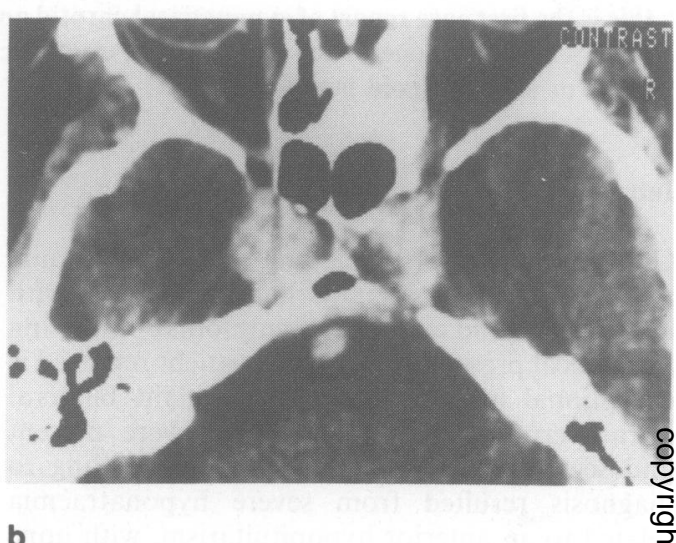

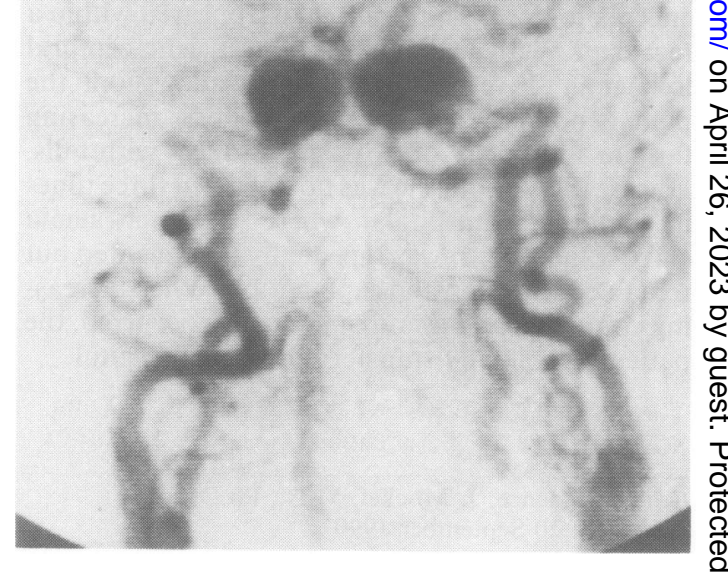


C

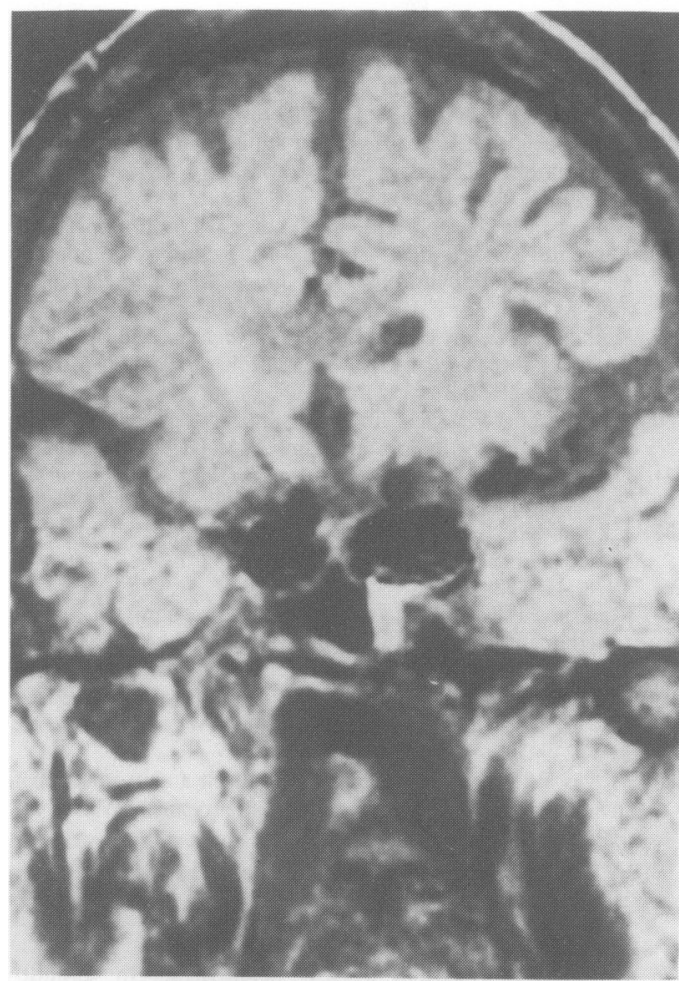

Figure 1 Radiological demonstration of the bilateral intrasellar carotid aneurysms by (a) intravenous contrast enhanced CT scan (axial view of the level of the sellar region); (b) digital venous angiography; (c) MRI: coronal slice (0.5 Tesla; SE, TR $1500 \mathrm{~ms}$, TE $30 \mathrm{~ms}$ ).

intrasellar carotid aneurysms and pituitary insufficiency. ${ }^{10,15-20}$ In contrast to our patient, the clinical symptoms leading to investigation and diagnosis of all these cases were related to the neurological manifestations of basal intracranial aneurysms: severe headache, oculomotor palsies, visual failure, sudden exophthalmos and subarachnoid haemorrhage, while documentation of partial or complete hypopituitarism was a secondary by-product of the complete medical workup of the patients. Our patient had transient diplopia 10 months before admission, but this symptom was not spontaneously reported.

The exceptional clinical presentation of our case should discard the general rule excluding the diagnosis of an intracranial carotid aneurysm in the absence of any concomitant focal 'mass effect'. ${ }^{12,21}$ The pathogenesis of pituitary dysfunction induced by intracranial aneurysms remains uncertain for two main reasons: (1) the necropsy reports do not often describe the pathology of the pituitary and hypothalamus; ${ }^{16,17}$ the endocrine evaluation was frequently incomplete and postoperative dynamic pituitary function testing was rarely performed. Direct destruction of the pituitary by compression and ischaemic necrosis has been suggested by some, ${ }^{10,18}$ but the largest carotid aneurysm in a series was in a young woman who had borne a child 6 months earlier. ${ }^{16}$ The hypothesis of compression of the hypothalamus compromising the secretion of releasing factors, and inducing hyperprolactinaemia as in our case, seems more tenable. Indeed, Verbalis et al. ${ }^{17}$ have described the complete reversal of a severe hypopituitarism with hyperprolactinaemia after clipping of a giant carotid aneurysm in a 59 year old woman. Although the aneurysms of our patient were most likely responsible for this hypopituitarism, such a clear cut causal relationship cannot be established. Diagnostic confusion can certainly arise from the coincidental occurrence of aneurysms with secreting or non-functional pituitary adenomas, disclosed by systematic angiography in $6.7 \%$ of such tumours. ${ }^{22}$

Another peculiarity of our patient was the presence of symmetrical intracavernous aneurysms of both internal carotid arteries. Multiple aneurysms represent $20 \%$ of all intracranial aneurysms, with a strong tendency to occur symmetrically, particularly when the internal carotid or middle cerebral arteries are affected..$^{23-25}$ Of all double aneurysms, when one arises on an internal carotid artery, the second one will be on the contralateral carotid in $49 \%$ of the cases with a better than $3: 1$ chance of being symmetrically disposed. $^{23}$

For the radiologist, carotid aneurysm is a well known differential diagnosis for an apparent intrasellar tumour with lateral extension; bilateral aneurysms are, however, exceptional. Angiography is systematically performed in order to rule out this uncommon aetiology, particularly when a transsphenoidal approach of the lesion is planned. MRI appears to be a very valuable diagnostic tool as it shows vascular elements without any contrast injection: flow sensitivity is indeed one of the major advantages of MRI. Rapid flowing blood appears usually as areas without any signal intensity while slow flowing blood appears hyperintense (paradoxical enhancement) ${ }^{26,27}$ As a consequence, MRI allows easy differentiation between carotid arteries and cavernous sinus, and an aneurysm is demonstrated by a signal void black area while if thrombosed, a typical high signal intensity region identifies the lesion. 


\section{References}

1. Mitchell, S.W. Aneurysm of an anomalous artery causing anteroposterior division of the chiasm of the optic nerves and producing bitemporal hemianopia. J Nerv Ment Dis 1889, 16: 44-62.

2. Thomas, J.E. \& Ross, R.E. The parasellar syndrome: problems in determining etiology. Mayo Clin Proc 1970, 45: 617-623.

3. Raymond, L.A. \& Tew, J. Large suprasellar aneurysms imitating pituitary tumour. J Neurol Neurosurg Psychiatry 1978, 41: 83-87.

4. White, J.C. \& Ballantine, H.T. Intrasellar aneurysms simulating hypophyseal tumours. J Neurosurg 1961, 18: 34-50.

5. Rischbieth, R.H. \& Bull, J.W. The significance of enlargement of the superior orbital (sphenoidal) fissure. Br $J$ Radiol 1958, 31: 125-135.

6. Imura, H. Hypopituitarism. In: Imura, H. (ed) The Pituitary Gland. Raven Press, New York, 1985, pp. 501-525.

7. Major, P., Kuchel, O., Boucher, W., Nowaczynski, W. \& Genest, J. Selective hypopituitarism with severe hyponatremia and secondary hyporeninism. J Clin Endocrinol Metab 1987, 46: 15-19.

8. Burke, C.W. Adrenocortical insufficiency. Clin Endocrinol Metab 1985, 14: 947-976.

9. Davis, B.B., Bloom, M.E., Field, J.B. \& Mintz, D.H. Hyponatremia in pituitary insufficiency. Metabolism 1969, 18: $821-832$.

10. Bethune, J.E. \& Nelson, D.H. Hyponatremia in hypopituitarism. N Engl J Med 1965, 272: 771-776.

11. Strong, J.A. The pituitary gland. Clin Endocrinol Metab 1980, 9: 605-614.

12. Meadows, S.P. Intracavernous aneurysms of the internal carotid artery. Their clinical features and natural history. Arch Ophthalmol 1959, 62: 566-574.

13. Weinberger, L.M., Adler, F.H. \& Grant, F.C. Primary pituitary adenoma and the syndrome of the cavernous sinus: a clinical and anatomic study. Arch Ophthalmol 1940, 24: 1197-1205.

14. Sheehan, H.L. \& Summers, V.R. Syndrome of hypopituitarism. $Q J$ Med 1949, 18: 319-378.

15. Driesen, W. On two operative findings in space occupying intrasellar processes. Zbl Neurochir 1959, 19: 28-35.
16. Van 't Hoff, W., Hornabrook, R.W. \& Marrs, $\mathrm{V}$ Hypopituitarism associated with intracranial aneurysms. $B r_{C}$ Med J 1961, 2: 1190-1194.

17. Verbalis, J.G., Nelson, P.B. \& Robinson, A.G. Reversible $\overrightarrow{\vec{T}}$ panhypopituitarism caused by a suprasellar aneurysm: the contribution of mass effect to pituitary dysfunction. Neurosurg 1982, 10: 604-611.

18. Gallagher, P.G., Dorsey, J.F., Stefanini, M. \& Lonney, J.M. Large intracranial aneurysm producing panhypopituitarism $\vec{D}$ and frontal lobe syndrome. Neurology (New York) 1956, 6:气 829-837.

19. Kahana, L., Lebovicz, H., Lusk, W. et al. Endocrine manifes on tation of intracranial extrasellar lesions. $J$ Clin Endocrinolo Metab 1962, 22: 304-324.

20. Shantharam, V.V. \& Clift, G.V. Suprasellar aneurysm: an $\vec{\omega}$ unusual cause of hypopituitarism. JAMA 1974, 229: 1473.

21. Du Boulay, G.H. Some observations on the natural history ofo intracranial aneurysms. Br J Radiol 1965, 38: 721-757.

22. Jakubowski, J. \& Kendall, B. Coincidental aneurysms with tumours of pituitary origin. $J$ Neurol Neurosurg Psychiatry 1978, 41: 972-979.

23. Locksley, H.B. Report on the cooperative study of intracranial aneurysms and subarachnoid hemorrhage. Section $\mathrm{V} \cdot \mathrm{in}_{\mathrm{N}}$ Part I. Natural history of subarachnoid hemorrhage, intracranial aneurysms and arteriovenous malformations. Based on 6368 cases in the Cooperative study. J Neurosurg 1966, 25:219-239.

24. Moyes, P.D. Surgical treatment of multiple aneurysms and of incidentally discovered unruptured aneurysms. J Neurosurg 1971, 35: 291-295.

25. Garza-Mercado, R., Rangel, R.A. \& Garza-Vazquez, J.F. Coexistence of bilateral aneurysms of the internal carogid $\vec{\omega}$ arteries and an arteriovenous malformation of the left fron lobe. Surg Neurol 1984, 21: 267-271.

26. Norman, D. Vascular disease: hemorrhage. In: Bran Zawadzki, M. \& Norman, D. (eds) Magnetic Resonañce Imaging of the Central Nervous System. Raven Press, New York, 1988, pp. 209-220.

27. Krishna, C.V.G.R. \& Lee, S.H. Cerebrovascular anomalies. In: Stark, D.S. \& Bradley, W.G. (eds) Magnetic Resonance 2 Imaging. C.V. Mosby, St Louis, USA, 1988, pp. 473-505. 